\title{
O papel das diretivas antecipadas como respaldo legal ao médico com paciente idoso com demência
}

\author{
Jéssica T. Casella, ${ }^{1 *}$ Virgílio G. Moreira ${ }^{2}$
}

\section{Resumo}

Introdução: O prolongamento da sobrevida das pessoas idosas, aliada ao avanço no tratamento de doenças crônicas têm aumentado a prevalência de pessoas funcionalmente dependentes. O avanço dos recursos propedêuticos e terapêuticos da medicina nas últimas décadas trouxe a distanásia como efeito colateral.Fenômeno relativamente recente na sociedade tem suscitado discussões de cunho clínico, bioético e jurídico, com a finalidade de equacionar dilemas e modernizar as leis, adaptando-se a essa nova realidade. Objetivos: Analisar o papel das diretivas antecipadas de vontade no contexto do cuidado paliativo. Metodologia: Foi realizada uma revisão narrativa investigando artigos publicados na Revista de Bioética do Conselho Federal de Medicina do Brasil e suas últimas resoluções nos últimos dez anos. Para tanto, foram levantados dados atuais, no contexto jurídico, analisando o respaldo legal do processo decisório a cargo do médico geriatra. Resultado: Foram identificados nove artigos e três resoluções principais. Conclusões: No Brasil ainda não há legislação específica sobre o tema. Apesar do novo Código de Ética Médica ter representado um grande avanço, não foi suficiente ainda para introduzir essa prática na relação médico-paciente. Atualmente, as diretivas antecipadas de vontade são válidas à luz das normas constitucionais vigentes.

Descritores: Diretivas antecipadas; Doença de Alzheimer; Bioética.

\section{Abstract \\ The role of advance directives as legal support for medical aproach in the elderly with dementia.}

Introduction: The prolongation of the survival of the elderly and the progress in the treatment of chronic diseases has increased the prevalence of functionally dependent persons. The advancement of the therapeutic and therapeutic resources of medicine in the last decades has brought dysthanasia as a side effect. A relatively recent phenomenon in society has led to discussions of a clinical, bioethical and juridical nature, in order to solve dilemmas and modernize laws, adapting to this new reality. Objectives: To analyze the role of advance directives in the context of palliative care. Methodology: A narrative review was carried out investigating articles published in the Journal of Bioethics of the Federal Medical Council of Brazil and its last resolutions in the past ten years. To this end, current data was collected in the legal context, analyzing the legal support of the decision-making process by the geriatrician. Result: There were identified nine articles and three main resolutions. Conclusions: In Brazil, there is no specific legislation on the subject. Although the new Code of Medical Ethics represented a breakthrough, it was not

\author{
1. Hospital Adventista Silvestre. Rio de Janeiro, RJ, Brasil. \\ 2 Laboratório de Envelhecimento Humano - GeronLab. Faculdade de \\ Ciências Médicas. Universidade do Estado do Rio de Janeiro. Rio \\ de Janeiro, RJ, Brasil.
}

\author{
*Endereço para correspondência: \\ Rua Muniz Barreto, 396/503 \\ Rio de Janeiro, RJ, Brasil. CEP: 22251-090. \\ E-mail: jessycasella@gmail.com
}

Revista HUPE, Rio de Janeiro, 2017;16(2):96-101

doi: 10.12957/rhupe.2017.37649

Recebido em 16/08/2018. Aprovado em 16/08/2018.

enough to introduce this practice into the physician-patient relationship. Currently, the advance directives of Will are valid in light of the constitutional norms in force.

Keywords: Advance directives; Alzheimer disease; Bioethics.

\section{Resumen}

El papel de directivas anticipadas como respaldo legal al médico con paciente anciano con demência

Introducción: La prolongación de la supervivencia de las personas mayores, aliada al avance en el tratamiento de enfermedades crónicas, la prevalencia de personas dependientes funcionalmente ha aumentado. El avance de los recursos propedéuticos y terapéuticos de la medicina en las últimas décadas ha traído la distanasia como efecto colateral. El fenómeno relativamente reciente en la sociedad ha suscitado discusiones de carácter clínico, bioético y jurídico, con la finalidad de ecuacionar dilemas y modernizar las leyes, adaptándose a esa nueva realidad. Objetivos: Analizar el papel de las directivas anticipadas de voluntad en el contexto del cuidado paliativo. Metodología: Se realizó una revisión narrativa investigando artículos publicados en la Revista de Bioética del Consejo Federal de Medicina de Brasil y sus últimas resoluciones en los últimos diez años. Para eso, se levantaron datos actuales, en el contexto jurídico, analizando el respaldo legal del proceso decisorio a cargo del médico geriatra. Resultado: Se identificaron nueve artículos y tres resoluciones principales. Conclusiones: En Brasil todavía no hay legislación específica sobre el tema. A pesar del nuevo Código de ética médica haber representado un gran avance, no fue suficiente todavía para introducir esa práctica en la relación médico-paciente. Actualmente, las directivas anticipadas de voluntad son válidas a la luz de las normas constitucionales vigentes. 
Palabras clave: Directivas anticipadas; Enfermedad de Alzheimer; Bioética.

\section{Introdução}

A população idosa vem aumentando em todo o mundo, especialmente nos países em desenvolvimento. A perspectiva é que, em 2025, o Brasil venha a ser o sexto país do mundo em número de idosos. ${ }^{1}$ Os transtornos mentais sofrem influência desta mudança populacional, tornando os quadros de demência cada vez mais prevalentes na população que envelhece. Dados da literatura indicam que a cada cinco anos é observada a tendência da duplicação desta prevalência. ${ }^{2-3}$

Demência é uma síndrome causada por doenças de curso crônico, progressivo, que afetam diversas funções cerebrais, como a memória, a compreensão, o raciocínio, a orientação, o pensamento, a capacidade de aprendizagem, a linguagem, o juízo crítico, o comportamento e a habilidade de executar atividades do dia a dia.Portanto, são caracterizadas por declínio cognitivo que interfere no desempenho social ou profissional do individuo. Essa condição limita de forma importante a capacidade de autodeterminação. A demência é uma das principais causas de dependência e incapacidade na velhice, e a doença de Alzheimer é a causa mais prevalente. ${ }^{4-5} \mathrm{~A}$ perda de autonomia e independência passa a ser mais contundente com a idade avançada e a prevalência destas doenças degenerativas. A bioética clínica surge neste contexto para tentar equacionar dilemas éticos.

No Brasil, a proteção à pessoa idosa se faz basicamente por meio da Constituição Federal de 1988, que assegura o direito à dignidade da pessoa humana. Os princípios hipocráticos sempre foram referência moral e ética para a conduta médica. Contudo, com a Era Contemporânea, sobretudo a partir da década de 1970, os avanços tecnológicos na propedêutica e terapêutica médica passam a criar situações inéditas, nas quais se fizeram necessárias a sistematização e modernização dos referenciais éticos para a tomada de decisões. ${ }^{6}$

No termo "bioética" bios representa o conhecimento biológico, e ética, o conhecimento dos valores humanos. A Bioética surge, então, como ponte entre a ciência biológica e a ética. ${ }^{7}$ Muito emblemática e ilustrativa dessa nova "demanda ética" foi a criação do primeiro programa de hemodiálise na cidade de Seattle, em 1962, considerada como o marco da necessidade de modernizar a ética hipocrática em favor de uma "ética principialista", que nasceria em breve..$^{8}$ O dilema criado era simples: a logística (recursos disponíveis) não era capaz de ofertar o tratamento salvador da vida a todos os pacientes que dele necessitavam; era necessário criar critérios de seleção de pacientes. Vemos então surgir o esboço do primeiro "Comitê de Ética", com o árduo desafio de selecionar qual paciente iria se beneficiar do tratamento e, portanto viver; e qual paciente seria alijado, sendo relegado à morte inexorável. Não havia, até então, ferramentas metodológicas para equacionar este dilema.

Na década de 70, o obstetra holandês Andre Hellegers cria o chamado Instituto Kennedy de Ética, fomentando a discussão deste tema de extrema relevância na prática clínica. ${ }^{8}$ Ao final desta década o avanço nas pesquisas clínicas em seres humanos demanda um referencial normativo, visando salvaguardar a ética e o respeito à dignidade humana. Surge então o Relatório Belmont, elaborado pela Comissão nacional para a Proteção de Sujeitos Humanos na Pesquisa Biomédica e Comportamental, principal referência no campo da bioética. ${ }^{9}$ A sociedade vê emergir dois autores de suma importância: Tom Beauchamp e James Childress, que em 1979 estabeleceram os paradigmas que alicerçaram a chamada Teoria Principialista. Até hoje estes são fortes referenciais no embasamento e na instrumentação dialética à análise de valores em conflito: beneficência (praticar o bem), não maleficência (não causar danos), autonomia (autodeterminação) e justiça (liberdade e equidade). ${ }^{9}$ Surge então a chamada "bioética clínica", ramo da bioética que visa auxiliar a resolução de conflitos e dilemas éticos à beira do leito, na sala de cirurgia e nos consultórios. ${ }^{10}$

Bioética, aumento da expectativa de vida, expansão das doenças crônicas e a discussão da qualidade de vida também trouxeram reflexões sobre a qualidade de morte daqueles que estão diante da finitude. Nesse cenário, a moderna abordagem dos cuidados paliativos visa resgatar a dimensão integrativa do paciente. Vemos surgir com aquela que é considerada a "mãe dos cuidados paliativos", Cicely Saunders, o conceito de "dor total": a extrapolação da concepção da dor na sua dimensão puramente física, buscando compreender seuss aspectos emocionais, sociais e espirituais. Atualmente o Cicely Saunders International é uma entidade multicêntrica, internacional com foco em pesquisas 


\section{Artigo de revisão}

sobre como melhorar o tratamento dos sintomas das doenças graves, entre elas, a síndrome demencial.

Com a demanda provocada pela modificação dos perfis epidemiológicos e demográficos e a necessidade de proteção ao final da vida, a Organização Mundial de Saúde (OMS) define cuidados paliativos como uma abordagem que melhora a qualidade de vida dos pacientes e de seus familiares que estejam enfrentando problemas associados a doenças críticas, pela prevenção e alívio de sofrimento por meio da identificação precoce, avaliação cuidadosa e tratamento da dor e outros problemas físicos, psicossociais e espirituais. Os cuidados paliativos devem começar no momento do diagnóstico de uma doença grave e ameaçadora à vida. ${ }^{11}$ Antes estes cuidados eram enfatizados quando se "fechava o prognóstico" e rotulações contundentes como "fora de possibilidades terapêuticas" fulminavam a esperança de familiares, despreparados emocionalmente para o luto do porvir. Estes rótulos e outras afirmações como "não há mais nada a fazer pelo paciente" tornaram-se anacrônicos, ultrapassados. Com o aumento da expectativa de vida, houve demanda por ampliação dos horizontes da medicina, já que a tradicional medicina centrada no ataque à doença não estava adequada para tratar dos portadores de patologia crônica. ${ }^{12}$

Os cuidados curativos passam a dividir espaço com uma abordagem que visa também à qualidade de vida do paciente e de seus familiares. Fala-se hoje em "proporcionalidade das intervenções" e habilidades médicas como a comunicação empática e sensível com o paciente e seus familiares passam a compor as potencialidades sine qua non ao bom médico, vital ao bom desfecho do curso clínico de uma doença, mesmo que o óbito seja constatado ao final. Estas tendências estão em consonância com os consensos de fim de vida das principais entidades médicas no mundo. ${ }^{13}$

As Diretivas Antecipadas de Vontade (DAV) trazem uma tentativa de resolução de dilemas éticos vividos na relação médico-paciente-família. Elas surgem para assegurar ao paciente o direito de se recusar a ser submetido a tratamento médico focado exclusivamente no prolongamento de vida em situações em que a cura para a morbidade observada não seja viável. Este seria o documento que nortearia suas decisões diante de situações adversas. Assim, é introduzida na área dos cuidados médicos, quando estamos frente a uma situação sem possibilidade de cura, a oferta de cuidados paliativos. Essa filosofia de cuidados é uma proposta de abordagem integral à pessoa, indo ao encontro das necessidades físicas, psíquicas, sociais e espirituais quando estamos frente a uma pessoa com doença crônico-degenerativa ou sem prognóstico positivo ou em fase final de vida. Em suma, resgatamos a perspectiva da dignidade também no processo do morrer.

No artigo primeiro da resolução 1.995/2012 do Conselho Federal de Medicina (CFM), as DAV são definidas como um conjunto de desejos, prévia e expressamente manifestados pelo paciente, sobre cuidados e tratamentos que quer, ou não, receber no momento em que estiver incapacitado de expressar sua vontade de maneira livre e autônoma. Entretanto, este é um documento de um órgão de classe com força normativa somente entre os médicos e é limitado quanto à regulamentação das vias legais de formalização. Até o momento atual existe um número ínfimo de associações civis e inexiste, no Brasil, uma legislação outorgada para tal. Incentivos da Academia Nacional de Cuidados Paliativos (ANCP) e da Comissão Permanente de Cuidados Paliativos da Sociedade Brasileira de Geriatria e Gerontologia (SBGG) estão na vanguarda juntamente à equipe do Direito, promovendo fóruns e reflexões conjuntas dada a relevância e necessidade do tema em nossa realidade. $\mathrm{O}$ presente estudo tem como objetivo analisar o papel das DAV no contexto dos cuidados paliativos como instrumento proposto para equacionar parcialmente conflitos éticos advindos de condutas médicas em pacientes já impossibilitados de exercerem sua autonomia por serem portadores de doença neurológica degenerativa e o respaldo legal à conduta médica no paciente portador de demência.

\section{Metodologia}

A metodologia consistiu em uma revisão narrativa baseada na legislação brasileira vigente. Foi realizada uma revisão de artigos publicados na Revista de Bioética do Conselho Federal de Medicina do Brasil e suas resoluções nos últimos dez anos utilizando a busca de publicações associadas à DAV e cuidados paliativos. Além disso, para melhor compreensão do tema, os marcos históricos e evolutivos ao longo dos últimos 30 anos no âmbito da Bioética Clínica, Cuidados Paliativos e a Legislação Brasileira em vigor serão apresentados no contexto metodológico.

\section{Discussão}

Foram identificados três resoluções principais e nove artigos. (Tabelas 1 e 2)

No Brasil, a discussão jurídica sobre mecanismos garantidores da autonomia do paciente gravemente enfermo ganha projeção nacional com a lei estadual 
Tabela 1. Principais resoluções sobre diretivas antecipadas de vontade propostas pelo Conselho Federal de Medicina (CFM) nos últimos 30 anos

\section{Resoluções:}

1. No ano de 2006 , foi publicada a Resolução 1.805 que versa sobre aspectos éticos, bem como suas consequências disciplinares, que envolvem a morte digna.

2. No ano de 2009, uma nova norma foi publicada, agora com caráter mais abrangente, criando o novo Código de Ética Médica (CEM): Resolução n. 1.931/2009.

3. Em 2012 o CFM publica no Diário Oficial da União a Resolução n. 1.995/12 que normatiza as Diretivas Antecipadas de Vontade no Brasil.

Tabela 2. Artigos publicados na Revista de Bioética Clínica sobre diretivas antecipadas de vontade nos últimos $\mathbf{3 0}$ anos

\begin{tabular}{l}
\hline Artigos: \\
1. Conhecimento de estudantes de medicina sobre o \\
testamento vital \\
2. Percepção de pacientes oncológicos sobre \\
terminalidade de vida \\
3. Diretivas Antecipadas de Vontade: um modelo \\
brasileiro
\end{tabular}

4. Testamento vital: o que pensam profissionais de saúde?

5. Diretivas Antecipadas de Vontade: benefícios, obstáculos e limites

6. Reflexos jurídicos da Resolução CFM 1.995/12

7. Testamento vital na prática médica: compreensão dos profissionais

8. Manifestação das vontades antecipadas do paciente como fator inibidor da distanásia

9. A caminho da morte com dignidade no século XXI

10.241, em São Paulo, também conhecida como "Lei Mário Covas", de 1999. Recém diagnosticado portador de câncer de bexiga em estágio avançado, o então governador do Estado de São Paulo, sancionou esta lei na qualidade de gestor e paciente. Ele viria a falecer dois anos depois com recusa a tratamentos extraordinários. Essa nova lei garantia o direito a recusar tratamentos dolorosos e que só oferecem prolongamento precário e penoso da vida. ${ }^{14}$

O Conselho Federal de Medicina no Brasil é uma autarquia paraestatal que tem a prerrogativa de expedir regulamentos que irão operacionalizar a lei, que possui uma "linguagem aberta". Podemos observar esta realidade se inferirmos que a interpretação constitucional baseada no princípio fundamental da dignidade da pessoa humana e no direito à vida leva à concepção de que a Constituição Federal protege o direito à morte digna, embora inexista norma federal que disponha sobre o tema. Surge então uma lacuna normativa que origina uma insegurança jurídica relevante por parte dos médicos de sofrer punição judicial pela prática da ortotanásia. ${ }^{15}$

Nas palavras do juiz de direito José Henrique Torres: "O temor em face da responsabilização ética, civil e criminal pela morte tem conduzido os médicos a promoção da distanásia". ${ }^{16}$ Este temor por parte dos médicos justifica-se ante a possibilidade de má interpretação da prática de ortotanásia e de repreensão na esfera profissional, podendo sofrer cassação de sua licença profissional; na esfera civil, com a possibilidade de indenização a terceiros; e na esfera penal, podendo ser condenado a cumprir pena.

O Conselho Federal de Medicina possui algumas resoluções cruciais para o desenvolvimento do debate em torno da manifestação da autonomia em situações de terminalidade. No ano de 2006, foi publicada a Resolução 1.805 que versa sobre aspectos éticos, bem como suas consequências disciplinares, que envolvem a morte digna. Interpretando equivocadamente a resolução do CFM, o Ministério Público solicitou à justiça federal a revogação da resolução, alegando que o CFM ultrapassara seu caráter normativo e legislara sobre aspectos imanentes à matéria penal, prerrogativa única do Congresso Nacional. A justiça federal expediu liminar que suspendeu a resolução.

Na resolução é descrito:

"Artigo 1": É permitido ao médico limitar ou suspender procedimentos e tratamentos que prolonguem a vida do doente, em fase terminal, de enfermidade grave e incurável, respeitada a vontade da pessoa ou de seu representante legal."

§1:으 "O médico tem a obrigação de esclarecer ao doente ou representante legal as modalidades terapêuticas adequadas para cada situação; $\$ 2^{\circ} \mathrm{A}$ decisão referida no caput deve ser fundamentada e registrada no prontuário; $3^{\circ}{ }^{\circ}$ É assegurado ao doente ou representante legal o direito de solicitar uma segunda opinião médica; $§ 4^{\circ} \mathrm{Em}$ se tratando de doente incapaz, ausente o representante legal, incumbirá ao médico decidir sobre as medidas mencionadas no caput deste artigo." 


\section{Artigo de revisão}

Artigo $2^{\circ}$ "O doente continuará a receber todos os cuidados necessários para aliviar os sintomas que levam ao sofrimento, assegurada a assistência integral, o conforto físico, psíquico, social, espiritual, inclusive assegurando a ele o direito de alta hospitalar."

O CFM emitiu então, nota esclarecendo as definições e conceitos de ortotanásia, distanásia e eutanásia. O MP reconheceu o equívoco de sua propositura e solicitou a justiça federal que sua própria ação fosse julgada improcedente. Superado o entrave judicial instaurado, a resolução 1805/06 voltou a vigorar, o que representou um grande avanço no que tange à relação médico-paciente e a autonomia deste. ${ }^{17}$

No ano de 2009, uma nova norma foi publicada, agora com caráter mais abrangente. Criando o novo Código de Ética Médica (CEM), a Resolução n. 1.931/2009 buscou consolidar a visão menos paternalista da medicina. Fica clara a orientação ética do Conselho Federal de Medicina de privilegiar a escolha do paciente. Dos artigos que mais se destacam:

Artigo 22 "Nas situações clínicas irreversíveis e terminais, o médico evitará a realização de procedimentos diagnósticos e terapêuticos desnecessários e propiciará aos pacientes sob sua atenção todos os cuidados paliativos apropriados".

E o artigo $41^{\circ}$ "Nos casos de doença incurável e terminal, deve o médico oferecer todos os cuidados paliativos disponíveis sem empreender ações diagnósticas ou terapêuticas inúteis ou obstinadas, levando sempre em consideração a vontade expressa do paciente ou, na sua impossibilidade, a de seu representante legal". ${ }^{18}$

Em 31 de Agosto de 2012 o CFM publica no Diário Oficial da União a Resolução n⒈995/12 que normatiza as DAV no Brasil:

"conjunto de desejos, prévia e expressamente manifestados pelo paciente, sobre cuidados e tratamentos que quer, ou não, receber no momento em que estiver incapacitado de expressar, livre e autonomamente, sua vontade."19

Este documento respalda a conduta médica em situações de conflito, protegendo profissionais de acusação de omissão de socorro ou eutanásia.

Esta pode ser anexada ao prontuário ou transcrita pelo médico, desde que autorizado pelo paciente, não sendo necessário assinatura ou testemunhas, dada a natureza da função do médico, que goza de fé pública e cujos atos têm efeito legal e jurídico.

É importante ressaltar que, para efeito jurídico, as diretivas tem caráter normativo apenas entre a classe médica, não se podendo afirmar que estejam, de fato, legalizadas no Brasil. Mas a publicação no DOU catalisou as discussões sobre o tema e cresce exponencialmente o número de DAV registradas nos cartórios brasileiros. ${ }^{20}$

Embora não tenha a prerrogativa de sancionar que as DAV sejam registradas em cartório, o CFM recomenda fortemente que isso seja feito, pois sua lavratura como escritura pública garante sua segurança jurídica.

\section{Conclusão}

No Brasil ainda não há legislação específica sobre o tema. Apesar do novo Código de Ética Médica ter representado um grande avanço, não foi suficiente ainda para introduzir essa prática na relação médicopaciente. Atualmente, as DAV são válidas à luz das normas constitucionais vigentes, dentre elas os princípios de dignidade da pessoa humana (art.1, inciso III), da autonomia (implícito no art.5), e a proibição de tratamento desumano (art.5, inciso III) garantidos na Constituição Federal de 1988 e o artigo 15 do Código Civil, que proíbe "constrangimento a submeter-se, com risco de vida, a tratamento médico ou intervenção cirúrgi$c a$ ". Em cenário nacional não há nenhuma associação civil que lute para pôr em prática esse registro. Não há nenhum projeto de lei específico que verse sobre o tema tramitando no Congresso Nacional. Além disso, há uma carência de material científico sobre o assunto. A maior parte dos profissionais de saúde desconhece o documento. Essa falta de regulamentação traz uma insegurança às pessoas que têm interesse de deixar sua vontade expressa e aos médicos que se veem diante de conflito quando diferem as vontades dos familiares. A relação médico-paciente, diante deste tipo de situação, está carente de proteção.

Portanto, é necessário despertar uma profunda reflexão sobre saúde e doença, autonomia e dependência, vida e morte na população como um todo. Precisamos que a discussão sobre o assunto avance na sociedade, para que leis possam efetivamente ser regulamentadas. Como pontapé inicial, em âmbito nacional, foi criado um fórum de discussão sobre o tema no endereço eletrônico www.testamentovital.com.br, por Dadalto e colaboradores, o que já facilita o acesso às informações. Além disso, foi proposto pela mesma autora um modelo para facilitar a elaboração do documento das DAV. Vale ressaltar que o documento sugerido é apenas um guia e deve ser individualizado à luz das peculiaridades de cada caso.

A participação do médico na feitura do documento 
também é fonte de importante reflexão. Embora a Resolução CFM 1995/12 tenha regulamentado que é papel do médico apenas registrar no prontuário os desejos do paciente, seu papel vai muito além disso: possuidor do conhecimento técnico, deve auxiliar o paciente na confecção da diretiva. Propõe-se que o médico responsável por acompanhar o paciente crônico seja coadjuvante neste processo, por conhecer mais profundamente o paciente e pelo vínculo de confiança já estabelecido. A autonomia do paciente só será plena se ele estiver muito bem informado sobre sua circunstância e sobre o papel de determinadas terapêuticas no curso clínico da doença.

\section{Referências}

1. Ramos LR, Veras RP, Kalache AA. Envelhecimento populacional: uma realidade brasileira. Rev. Saúde. Publ. 1987;21:211-224.

2. Jorm AF, Korten AE, Henderson AS. The prevalence of dementia: a quantitative integration of the literature. Acta Psychiatr Scand. 1987;76:465-479.

3. Lopes MA, Bottino CMC. Prevalência de demência em diversas regiões do mundo. Análise dos estudos epidemiológicos de 1994 a 2000. Arq. Neuro-psiquiatr. Mar. 2002;60(1):61-69.

4. Alzheimer's Disease International. World Alzheimer report 2015: the global impact of dementia an analysis of prevalence, incidence, cost and trends. London; 2015. http://www.alz.co.uk/research/world-report-2015 [acessado em 27 de agosto de 2015].

5. Freitas EV, Py L (Org.).Tratado de Geriatria e Gerontologia. 3. ed. [Reimpr]. Rio de Janeiro: Guanabara Koogan; 2013.

6. Figueiredo AM. Bioética clínica e sua prática. Revista Bioética, 2011;19(2): 343-58.

7. Pessini L, Siqueira JE. Bioética, envelhecimento humano e dignidade no adeus a vida. In: Freitas EV, Py L. (Org). Tratado de geriatria e gerontologia. $3^{a}$ ed., Rio de Janeiro: Guanabara Koogan; 2011. p.107-16.

8. Gracia D. Pensar a bioética: metas e desafios. São Paulo:
Loyola; 2010.

9. Beauchamp TL, Childress JF. Principles of biomedical ethics. New York: Oxford University Press; 1979.

10. Marques Filho J. Bioética clínica: cuidando de pessoas. Rev. Bras. Reumatol. 2008 Jan./Feb;48(1):31-3.

11. Hall S, Petckova H, Tsouros A, et al. World Health Organization: Palliative care for older people: better practices. Copenhagen, Dinamarca: World Health Organization; 2011.

12. Chaves JHB. Cuidados paliativos na pratica medica: contexto bioético. Rev. Dor [on-line]. 2011;12(3):250-255.

13 Forte DN. Associações entre as características de médicos intensivistas e a variabilidade no cuidado ao fim de vida em UTI [tese]. São Paulo: , Faculdade de Medicina; 2011 [citado 2018-08-17]. doi:10.11606/T.5.2011.tde-07122011-124313.

14. Conselho Federal de Medicina, Resolução CFM n1995, de 31 de agosto de 2012. Anexo Dispõe sobre as diretivas antecipadas de vontade dos pacientes. (internet).(acesso 30 de out.2014).Disponível em http://www.portalmedico.org.br/ resolucoes/CFM/2012/1995_2012.pdf

15. Monteiro da Cruz ML. A Licicitude Civil da Prática da Ortotanásia por Médico em Respeito à Vontade Livre do Paciente. Revista Bioética. 2013;21(3):405-11.

16. Torre JHR. Ortotanásia não é homicídio nem eutanásia. In: Moritz RD. (Câmara técnica sobre a Terminalidade da Vida e Cuidados Paliativos do Conselho Federal de Medicina). Conflitos bioéticos do viver e do morrer da morte. Brasília: CFM; 2011, p. 157-184; Disponível também em: http://www. portalmedico.org.br.

17. Toledo K. Justiça Federal derruba liminar e libera prática da ortotanásia no País. O Estado de S. Paulo, 2010, Dez 4.

18. Conselho Federal de Medicina, Resolução n.1.805, de 9 de novembro 2006 Disponível: http://www.portalmedico.org.br/ resolucoes/CFM/2006/1805_2006.htm

19. Conselho Federal de Medicina. Resolução no 1.995, de 31 de agosto de 2012. Dispõe sobre as diretivas antecipadas de vontade dos pacientes. [Internet]. (acesso 13 nov. 2012). Disponível: http://www.portalmedico.org.br/resolucoes/ cfm/2012/1995_2012.htm Anexo.

20. Mariz R. O direito de morrer: a hora do adeus. Correio Braziliense, 25 abr. 2012; Caderno bem estar: 57. 